\title{
THEMES AND PROSPECTS OF AUTOMATION AND ROBOTICS IN URBAN INFRASTRUCTURE RENEWAL
}

\author{
Tadashi Kanzaki \\ Dr. Prof., Faculty of Engineering, Kagawa University \\ 2217-20, Hayashi-cho, Takamatsu-city, Kagawa Prefecture, 761-0396 \\ kanzaki@eng.kagawa-u.ac.jp
}

\begin{abstract}
:
Called the urban arteries, the traffic is significantly affected by its congestion. One of the solutions to this is overpass, whose construction is forced to be amidst heavy traffic and thus extending the construction period. To deal with these situations, a crossing-over structure method have been developed in a range of sectors with a result that these few years have seen as many as 43 new work methods.

In contrast, another solution to the excessive concentration of urban traffic is the use of the underground. The underground space in major cities, however, is packed with a tangled web of subway systems, roads, and other lifelines, the situation which forces the use of underground at greater depths.

The paper examines these current situations and offers analysis and suggestions for the future direction in the technological development and issues to deal with.
\end{abstract}

Keywords: crossing-over structure method, cycled construction, folding type erection, rotation erection, air caster erection, construction at greater depths, long-distance transportation systems, conveyance and assembly of segments

\section{INTRODUCTION}

The expressways, railways, and various lifelines constructed during the high economic growth period in the 1960s make up a large proportion of the infrastructures in Japanese cities. Measures against aging infrastructures and to restore the functions of infrastructures have become a major problem for the Metropolitan Tokyo. Particularly vehicular transportation, as one of urban functions, is constantly delayed, which not only decreases efficiency and productivity but also adversely affects the living environment and life safety of citizens. The government is pressed to take necessary measures.

As solutions to the problems, attention is focused on the construction of an overpass or underpass to alleviate traffic congestion at the crossings, and on the construction of new urban transportation arteries at great depths. The challenge to both solutions is the various unprecedented constraints in constructing crossings and arteries, so automation and the use of robots in the construction are highly expected.

In this paper, the author analyzes the present state of new technologies for the renewal of urban functions, extracts problems, makes suggestions, and offers future prospects.

\section{RENEWAL OF URBAN FUNCTIONS: CLEARING UP TRAFFIC CONGESTION}

In Japan, traffic congestions seriously disrupt urban functions. The number of railway crossings that will not open for a considerably long time totals 1,000 across the country, of which 700 are in the in the 23 wards of Tokyo, which is 50 times more than in London. In addition, of
9,400 crossings in the 23 wards, overhead crossings number 81 , accounting for less than $1 \%$. According to a trial calculation, the economic

loss caused by traffic congestions due to deteriorated urban infrastructures is estimated at $¥ 435$ million and ¥338 million per kilometer in Tokyo and Osaka, respectively.

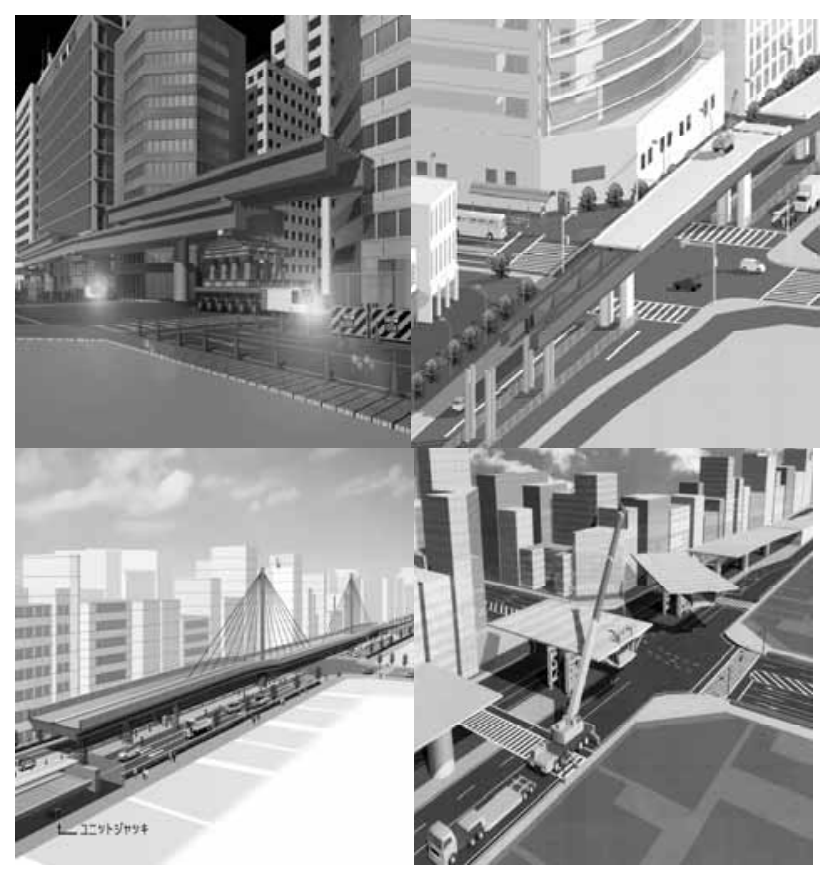

Figure 1. Construction methods of crossing-over structures 
The construction of overhead crossings will entail carrying out the work in the middle of traffic congestion and if conventional construction methods are used, it will take a long time to complete the work. For this reason, the government is hesitant about deciding on the implementation of the work. Against these backdrops, methods of rapidly constructing overhead crossings have recently been developed in many fields. According to a survey in 2005, as many as 43 new construction methods have been proposed.

\subsection{Fast construction by automation and systematization}

Various ingenious ideas for fast construction are incorporated into the methods. The following methods are proposed to shorten overall work periods: a method of erecting a prefabricated superstructure and substructure of single-piece construction in one day, a method of simultaneously constructing both superstructure and substructure, and a "cycled construction method" that efficiently combines many work types. The most important task in terms of schedule control is to enhance the efficiency of erecting a central girder at the crossing. For this purpose, many construction methods are proposed, as shown in Fig. 1 , including the methods of erecting the girder using a transfer car, by launching, with a crane, using a cable stay, and by setting in rotation. Figure 2 shows a method of erecting the girder using a transfer car equipped with air casters, with some thoughts put into designing the foundation and bridge pier to have the same cross section to downsize the overhead crossing. Figure 3 shows the method of unfolding a folded traffic lane section after erection to decrease traffic congestion as well as shorten work periods. The superstructure and substructure proposed by both methods are of single-piece construction. These methods aim at substantially shortening work periods by erecting the prefabricated superstructure and substructure in large blocks.

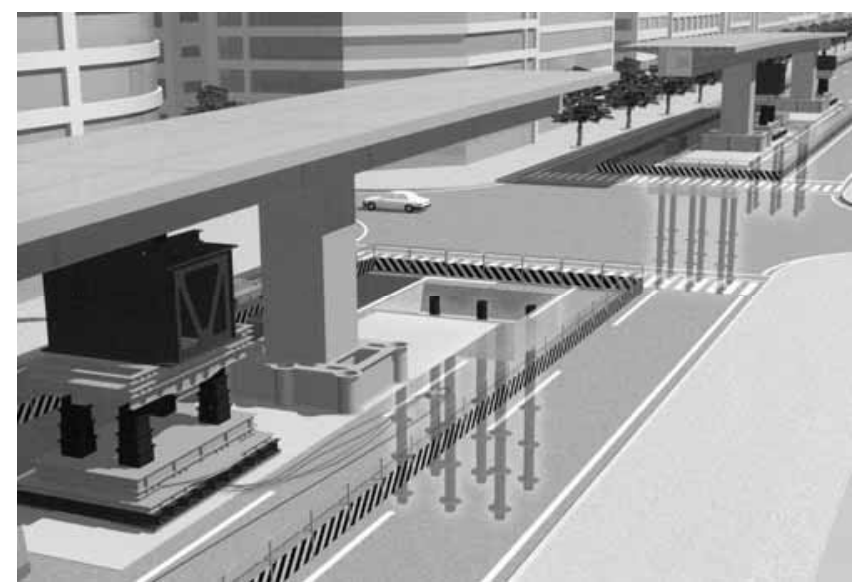

Figure 2. Method of erecting girder using a transfer car equipped with air casters

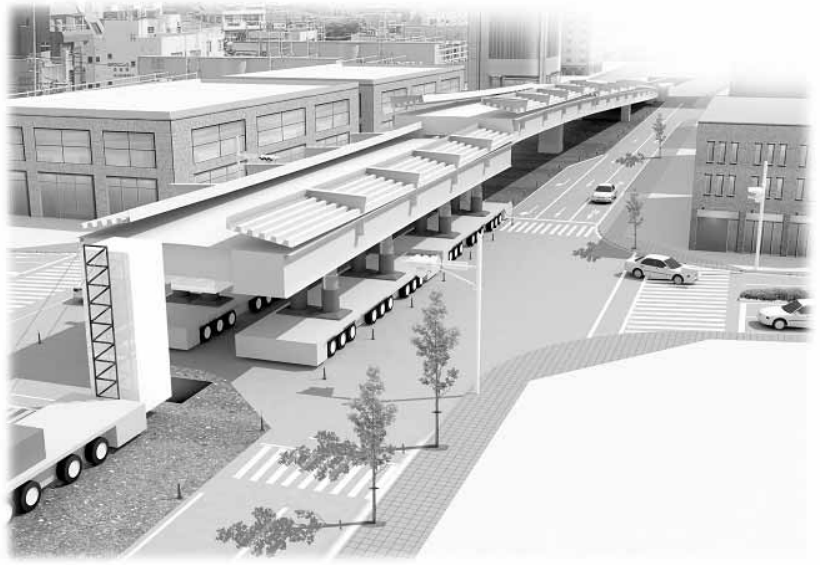

Figure 3. Method of unfolding a folded traffic lane section

2.2 Practical examples and effects of automation and robotics

In Osaka, Okayama, Kochi, Matsuyama under the jurisdiction of Chugoku and Shikoku Regional Development Bureaus of the Ministry of Land, Infrastructure and Transport, these fast construction methods have been adopted ahead of other bureaus in Japan and work periods have been substantially shortened. A bid system of design proposal type through integrated evaluation, or a system of making a comprehensive assessment of ideas and prices and placing an order for both design and construction, was adopted for the construction projects.

Figure 3 shows an execution example for the construction of an overhead crossing of the Okayama Bypass in Okayama Prefecture. This construction method for a viaduct, $50 \mathrm{~m}$ in the central span and $434 \mathrm{~m}$ in total length, has the following four advantages: the construction of a superstructure and substructure of single-piece structure is in parallel with foundation work; one block of $50 \mathrm{~m}$ long central girder at the crossing is erected during the night: PC well foundation and pier are of such construction that is jointed with a single column; and the superstructure is folded during erection and unfolded after erection, as shown in the figure.

These ideas shortened the conventional work period of 630 days to 510 days, a decrease of 120 days. The effect of shortening the work period is as shown in Fig. 4: that is, about 40 days were saved (33\% saving in the work period) by the construction of a superstructure and substructure of single-piece structure in parallel with foundation work and the erection of one block of central girder during the night; and about 30 days were saved (25\% saving in the work period) by the PC well foundation and pier of such construction that was jointed with a single column. In addition to the savings in the work periods, the substructure of single column construction in the center span allowed a 
right turn lane to be secured, which had the effect of decreasing traffic congestion. Further, the erection of folded superstructure increased the width of existing lanes by one lane and allowed the lane under the folded superstructure to be used immediately after the erection, which also had a great effect of reducing traffic congestion.

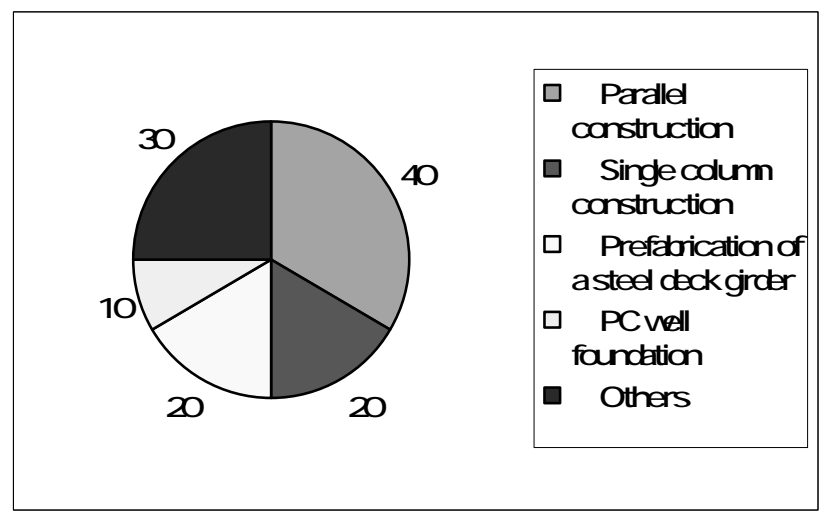

Figure 4. How the work period was reduced by 120 days

Figure 5 shows another execution example in Marugame City, Kagawa Prefecture. Adopting the new fast construction method shortened the conventional work period of 750 days to 320 days. The construction method is characterized by the superstructure and substructure of single-piece construction. According to a trial calculation, the single-piece construction had an effect of reducing the work period by 120 days. In addition, as shown in Fig.6, the following design changes contributed greatly to shortening the work period: reduction in soil reaction by widening footings; and construction of foundations eliminated by soil improvement.

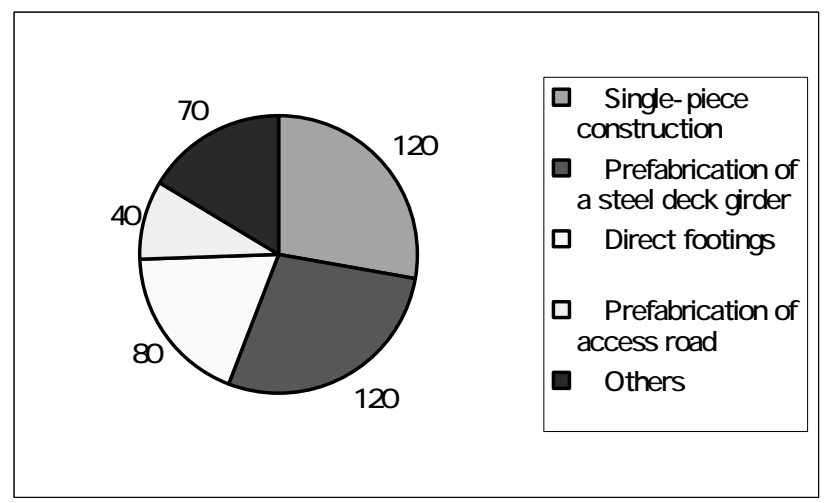

Figure 5 . How the work period was reduced by 430 days

Similarly, execution examples in Kochi and Matsuyama incorporated various design ideas. The conventional work period was shortened by $14-47 \%$ by the construction of a superstructure and substructure of single-piece construction, the erection of one block of girder in the center span, and the prefabrication of a steel deck girder.

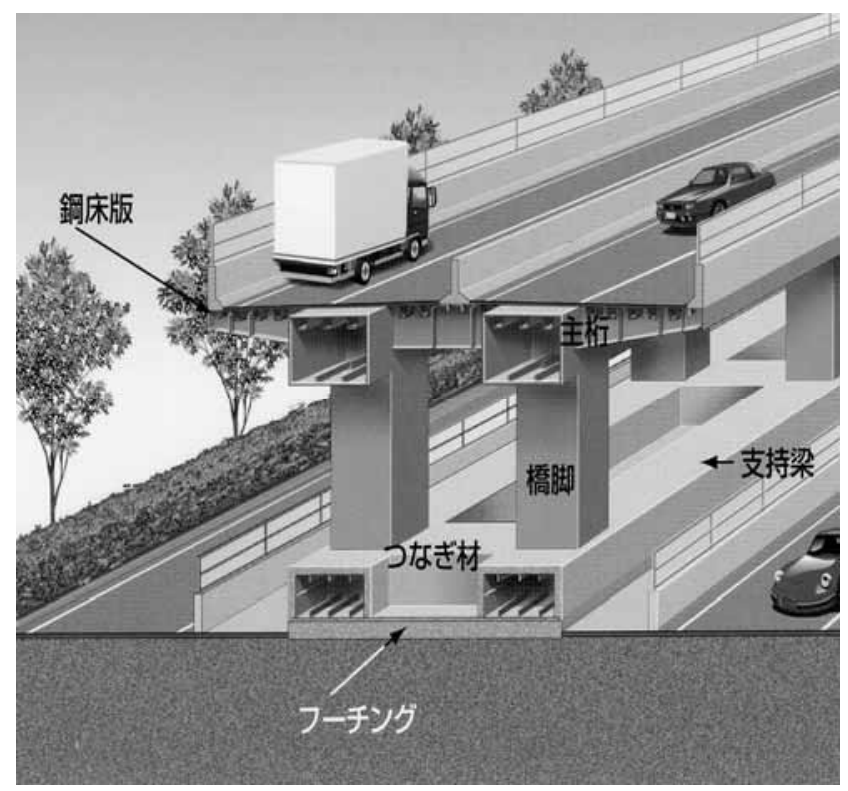

Figure 6. Fast construction in Marugame City

\subsection{Construction of crossings with an underpass}

Construction of crossings with an underpass is also proposed. Fig. 7 shows a large divided cross-section and shield tunneling method, i.e. a method of constructing a large cross-sectional tunnel by dividing the large cross-section into small sections and excavating individual small sections with a small cross-sectional shield machine. Fig.8 shows the protective outer shell tunneling method, i.e. a method of lining a tunnel with segments by excavating multiple small segment circle elements along the outer shell of the tunnel and jointing the elements under the ground.

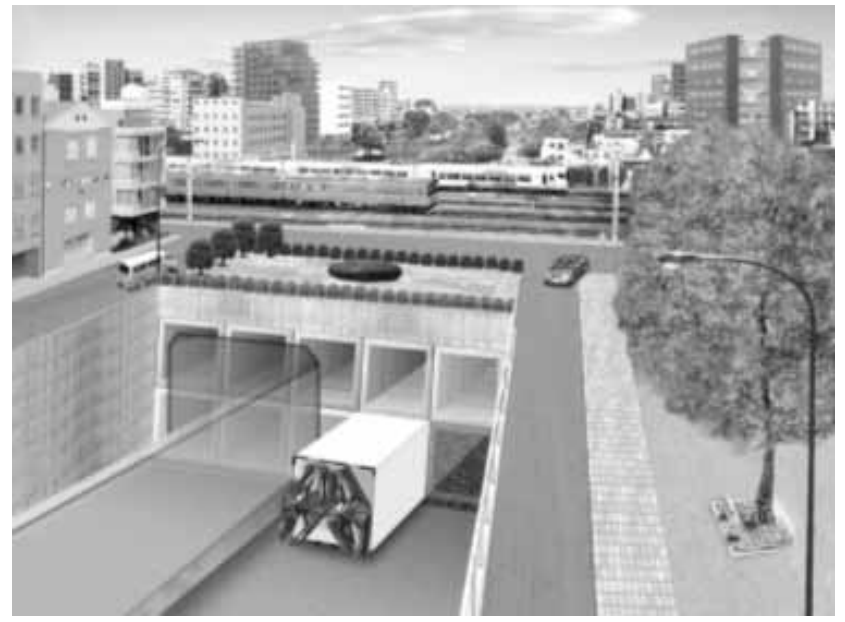

Figure7.Shield Tunneling Method with divided cross-section 


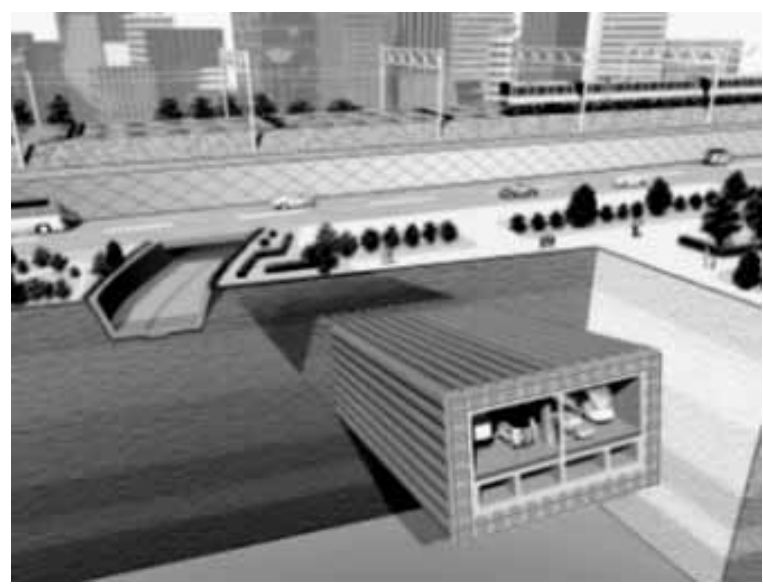

Figure 8. Protective outer shell Tunneling Method

\subsection{Challenges for the future}

These construction methods for multi-level crossings are being put into practical use in many fields. Although the utilization and development of the methods in the metropolitan area are expected, the underground spaces in the metropolitan area are full of subway and utility tunnels, which in some cases affect the construction of foundations. In addition, various problems, including the constraint in carrying out construction work and difficulty in securing a construction yard due to high density in the vicinity of construction sites, need to be solved.

\section{URBAN RENEWAL: CHALLENGES TO USING UNDERGROUND SPACES AT GREAT DEPTHS}

The Special Measures Act for Public Use of Deep Underground was enacted in April 2001, embarking on a new era of using underground spaces at great depths. The use of underground spaces in the metropolitan area began with the subway Ginza line $16 \mathrm{~m}$ below ground in 1934. As the subway lines form a complex network, underground spaces have been used at greater depths by necessity year after year: for example, the recently opened subway Oedo line runs at a depth of about $50 \mathrm{~m}$ below ground. In addition, a flood control underground basin is being constructed at great depths on the periphery of the metropolitan area.

3.1 Problems with the use of underground spaces at great depths and solutions

Because hydrostatic and soil pressures increase at great depths, it has become difficult to adopting only the conventional New Austrian Tunneling Method (NATM), and the shield tunneling method is used as the best method for the construction of underground spaces at great depths. It is necessary to reasonably solve the following problems with the use of underground spaces at great depths.
First is a large cross section. This increases the weight of tunnel segments, and it is necessary to devise a method of speeding up the erection of the segments and increasing the efficiency of erection.

Second is a wide variety of cross-sectional forms. Because tunnels with circular cross sections are uneconomical for stations and junctions on railways and roads, a technology of creating underground spaces with a wide variety of cross sections is required.

Third is long distance. A large amount of construction materials and surplus soil needs to be transported a long distance.

Fourth is speeding up and increasing efficiency. It is necessary to speed up construction work by automating each work type as well as increase the efficiency of the total construction system by synchronizing the work types.

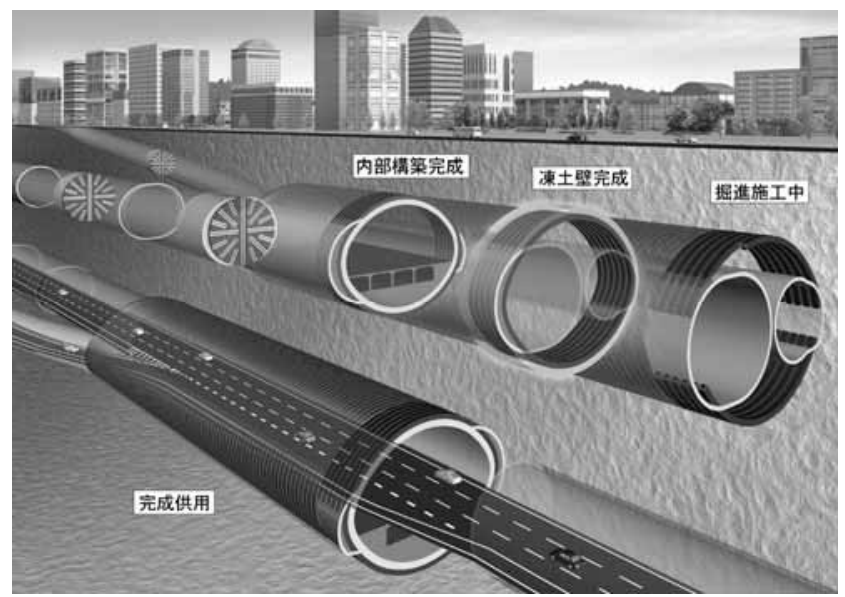

Figure 9. Large cross section Tunneling Method

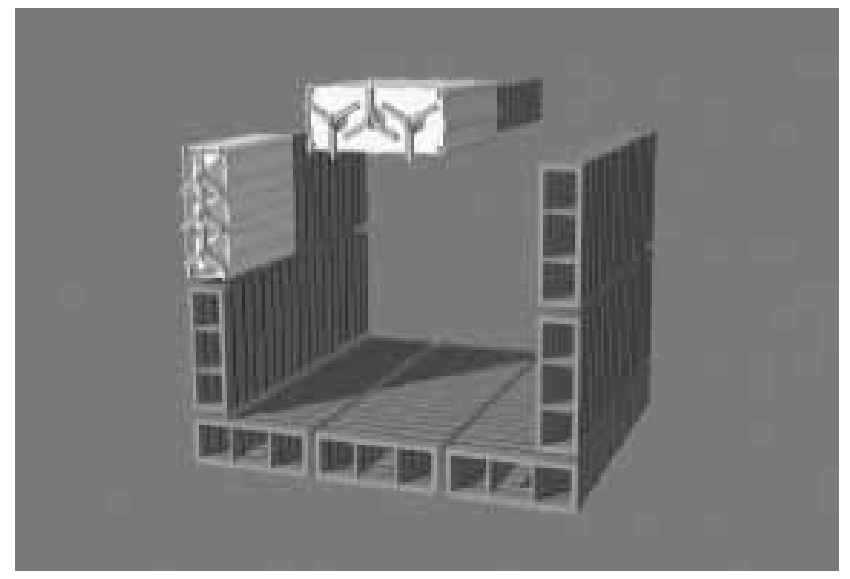

Figure 10. Multi-Micro Shield Tunneling Method 


\subsection{Present state of technological development}

Various technologies have been developed for creating underground spaces at great depths. New methods of excavating tunnels with arbitrary cross sections are proposed: for example, three-continuous consecutive circular type, circular joint type, elliptic type and free cross-sectional type. Figure 9 shows a method of constructing a tunnel with a large cross section from inside the tunnel using a pipe roof. Figure10,11shows a technology of constructing an underground space with a large rectangular cross section called the Multi-Micro-Shield-Tunnel (MMST.) As shown in the figure, this is a new construction method by which the outer walls called the outer shells are excavated with multiple small-scale shield machines, the shells are jointed, and the soil inside the shells is excavated to create a large underground space with a large cross section. This method was applied to the construction of the junction of the Shuto Expressway Kawasaki Longitudinal line.

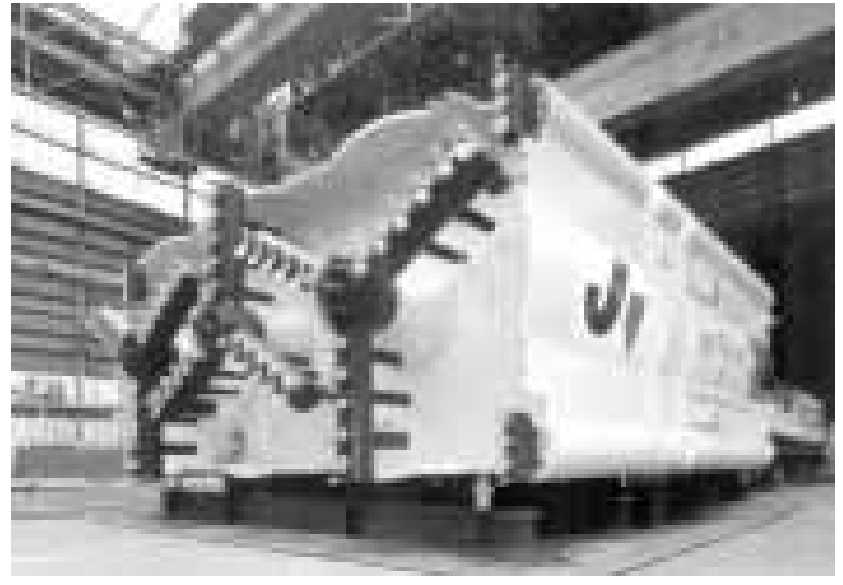

Figure 11. Multi-Micro Shield Tunneling Method

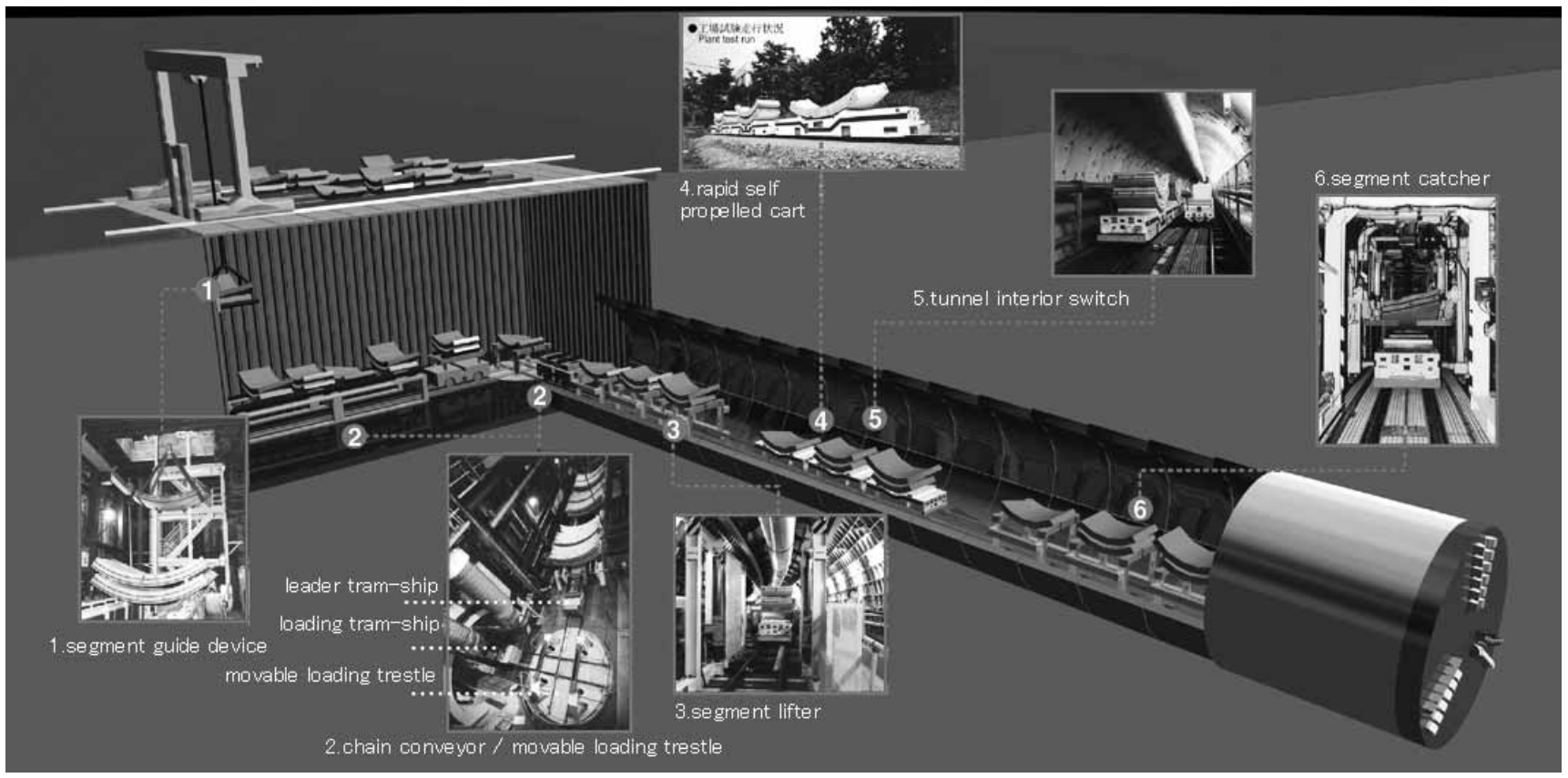

Figure 12. Segment Conveyance Robot

Various technologies have been developed to transport a large amount of construction materials and surplus soil a long distance. Figure 12 shows one of the technologies, or automation using robots to transport tunnel segments. Figure 13 shows the spherical shield tunneling method. This method was put into practical use for digging a tunnel with complete control in the longitudinal and transverse directions through a series of intricate underground spaces.

3.3 Present state and problems with automation and robotics in construction

As mentioned above, various shield tunneling technologies have been developed to ease urban congestion. The Committee on Automation and Robotics in Construction (chaired by Tadashi Kanzaki) of the Japan Society of Civil Engineers analyzed the present state of automation and use of robots in each shield tunneling process. Specifically, the committee evaluated 44 work types for the level of automation, cost and cost effectiveness, and analyzed problems with the automation. As a result, four out of 44 work types are fully-automated: that is, stabilization of a tunnel face when the shield machine advances; transportation of fluids; measurement of soil volume; and tertiary treatment of surplus soil. The number of work types 
semi-automated or automated on a trial basis is 34 , accounting for $77 \%$ of the total. This indicates that automation and the use of robots in shield tunneling work is increasing at a high rate. The committee stated in its report that it would be economical and safe to systematize other remaining work types to work cooperatively with humans rather than aim at fully automating the work types.

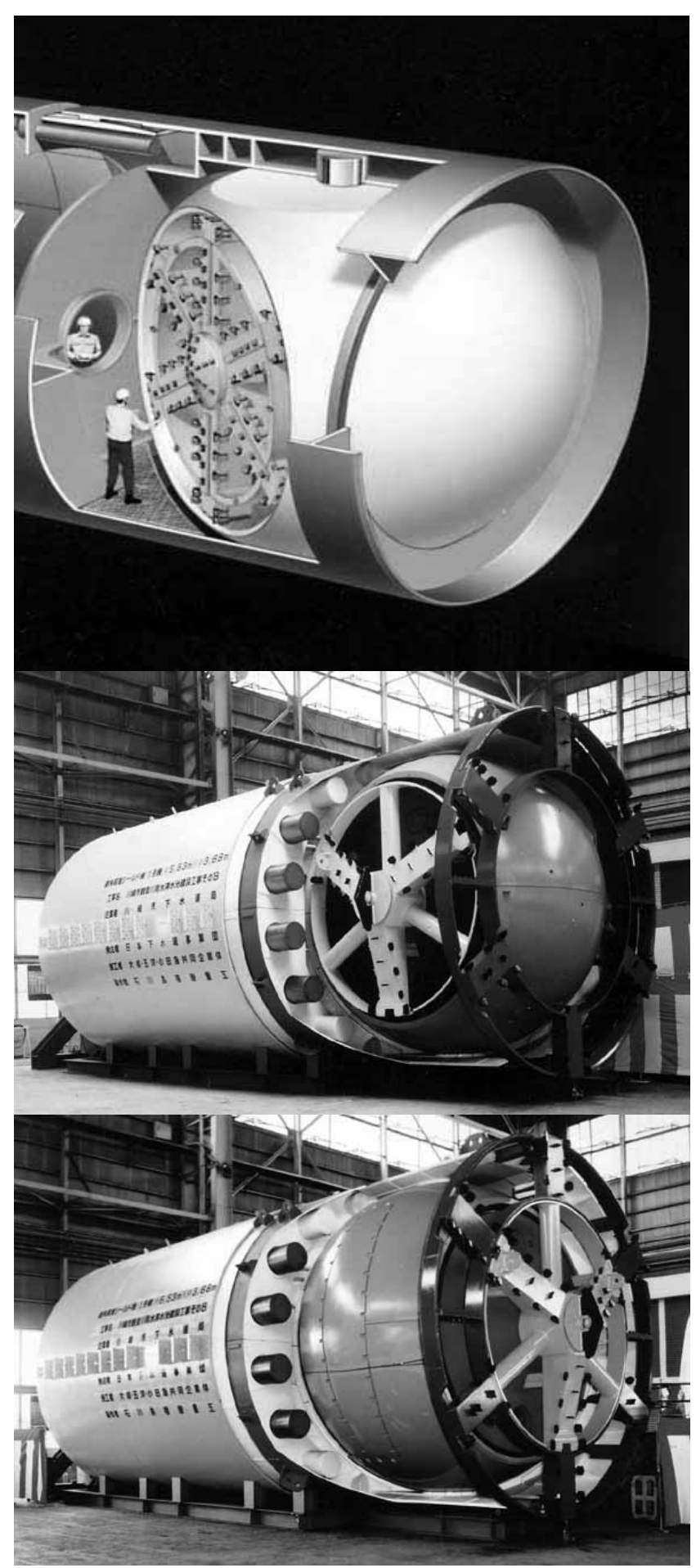

Figure 13. The Spherical Shield Tunneling Method
The committee also investigated factors obstructive to promoting the automation and use of robots in the construction. As a result, the major factor was the problem of cost, followed by the problem of scale. Although automation and use of robots on a trial basis are realized from a technical standpoint, human-intensive methods are in many cases selected from a cost standpoint. The committee pointed out equipment performance, maintenance and standardization as other obstructive factors.

\section{ACKNOWLEDGEMENTS}

Since its foundation in 1985, the Committee on Automation and Robotics in Construction of the Japan Society of Civil Engineers has been active in a variety of fields relating to automation and robotics in the construction industry. This paper presents some of the results of those activities. I would like to express my sincere thanks to the colleagues with whom I have worked.

I also would like to gratefully acknowledge Sumitomo Mitsui Construction Co.,Ltd., P.S.Mitsubisi Construction Co.,Ltd., Mitsubisi Heavy Industries Ltd., JFE Engineering Corporation, Taisei Corporation, Kajima Corporation, JST Co., Ltd. and Hitachi Zosen Corporation, for furnishing me with photos, materials, and information.

\section{REFERENCES}

[1] The Committee on Automation and Robotics in Construction of the Japan Society of Civil Engineers , " Prospects for automation and robotics in construction ", Jun.1992

[2] The Committee on Automation and Robotics in Construction of the Japan Society of Civil Engineers, " A view of automation and robotics in construction for the 21st century ” Dec.1996

[3] The Committee on Automation and Robotics in Construction of the Japan Society of Civil Engineers, "Prospects for automation and robotics in construction on the $21^{\text {st }}$ century ”,Jun.2001 